\title{
CHALLENGES IN BUILDING THE ADMINISTRATIVE CAPACITY OF CAREER CENTERS IN HIGHER EDUCATION INSTITUTIONS
}

\author{
R. Kirilov* \\ University of National and World Economy, Sofia, Bulgaria
}

\begin{abstract}
Purpose. An important priority for higher education institutions is the career development and realization of the students. In the dynamic labor market in Bulgaria this is becoming a serious challenge. It is important that these processes provide prerequisites for career centers to participate at all stages of the career path of students. The main objective of the present study is to build on the existing good practices and work of career centers to highlight the main factors for increasing their administrative capacity. Methods. The applied methods of study allow the basic objective to be achieved. These are: empirical analysis and synthesis, as well as an analysis of the existing regulatory framework. Results. The results obtained are in the direction of building and developing the administrative capacity of the higher education career centers. Conclusions. The conclusions outline the main challenges facing the higher education career centers and the opportunities for increasing their administrative capacity.
\end{abstract}

Key words: administrative capacity, administrative services, information technology, career centers

\section{INTRODUCTION}

In modern conditions, career centers of higher education institutions are a very important part of the structure. The arguments in this direction are focused on the strategically important task of higher education to focus mainly on higher quality. This quality is a multidimensional concept, one of which is a higher realization in the labor market. This study supports the concept that better career guidance and student development leads to a higher and better realization of the labor market. This, in turn, is one of the indicators for a higher quality of education. Developing the research problem in this direction should highlight the leading role of higher education career centers in these processes. Building and maintaining a higher administrative capacity is a guarantee for better results in career counseling for students. The present study attempts to formulate several main directions in which work should be done to increase capacity. On this basis, specific proposals are given for functional allocation by priorities and activities.

\footnotetext{
*Correspondence to: Rosen Kirilov, University of National and World Economy, Sofia 1700, tel. +35928195 693, e-mail: rkirilov@unwe.bg
}

\section{MAIN TASKS AT THE CAREER CENTERS}

The main tasks in the activities of the career centers of the higher schools in the last few years have significantly expanded and complicated. Such a situation is the result of the combination and mutual influence of several factors:

- Permanent changes in the labor market, from the point of view of demanded specialists;

- Digitization of the economy requiring the development of specific digital competences;

- Reducing intake of students in the higher education system;

- Wider presence of leading foreign employers on the Bulgarian market;

- Higher demand for realization by graduating students abroad;

- Demographic and migration factors, etc.

As a result of these and other factors, career centers in higher education institutions are challenged to seek and apply increasingly innovative approaches and career services to students. In this way, the main types of tasks are changed in the following three directions (Figure 1): 


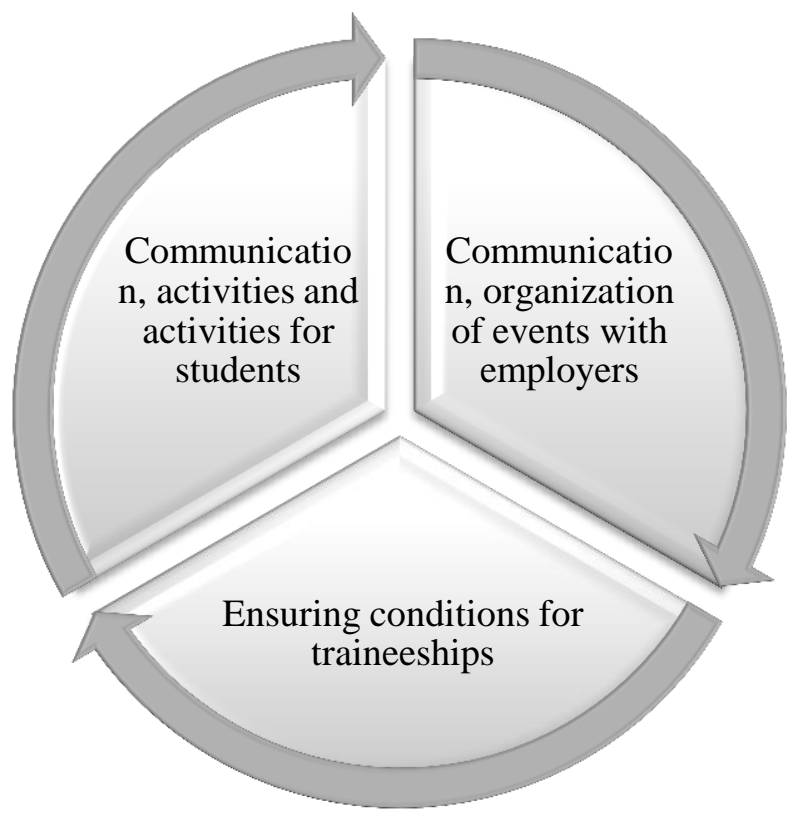

Figure 1. Basic types of tasks at the higher education career centers

These three types of tasks can be specified in the following directions $[1,2]$ :

- Expansion of communication and cooperation between the career center, faculties and departments of the higher school;

- Establishing and implementing a unified policy in the field of career support and professional development of students;

- Preparation of analyzes, reports and evaluations on the benefits of implementing the policies and the results of the organized events;

- Periodic preparation of analyzes of changes in the labor market;

- Carrying out analyzes of the achieved values of key performance indicators of the career center;

- Conducting information campaigns among students about the essence, mission, career center functions and benefits for each student;

- Conducting ongoing training on the peculiarities and characteristics of the career development lifecycle;

- Developing a policy of carrying out more internships and practical training for students;

- Providing information on announced positions of employers and current internship programs;

- Providing opportunities for permanent presence of employers in the digital channels of the higher school;
- Attract new employers;

- Developing and expanding career forums and more.

The proposed list of tasks is dynamic and depends on changes in the common career development policy. These exemplary tasks impose and require the search for approaches to increase the administrative capacity of career centers and to expand the services provided.

\section{OPPORTUNITIES FOR BUILDING AND EXTENSION OF ADMINISTRATIVE CAPACITY}

Administrative capacity is a complex and complex concept. In general, it is related to the ability of an organization to perform administrative processes and provide administrative services. The legal base is broad, basically it consists of the Administrative Procedure Code and the Administration Act. Several authors have been doing research in recent years. For example, in their study, Kirilova focuses on the importance of "different forms of access to administrative services and information about them", which is a leading principle in the regulatory framework [3]. Other authors explore the dynamics of data in the public sphere and the need to use information systems with dynamic content [4]. Career centers in higher education institutions are not typical representatives of administrative bodies but, by their very nature, provide public services of an administrative nature. They are for students as well as for 
employers. Structurally, career centers consist of departments or units in which career counselors work. They carry out career guidance and counseling for students. Building and maintaining a high level of administrative capacity for these structures is an important prerequisite for the provision of public services (Figure 2).

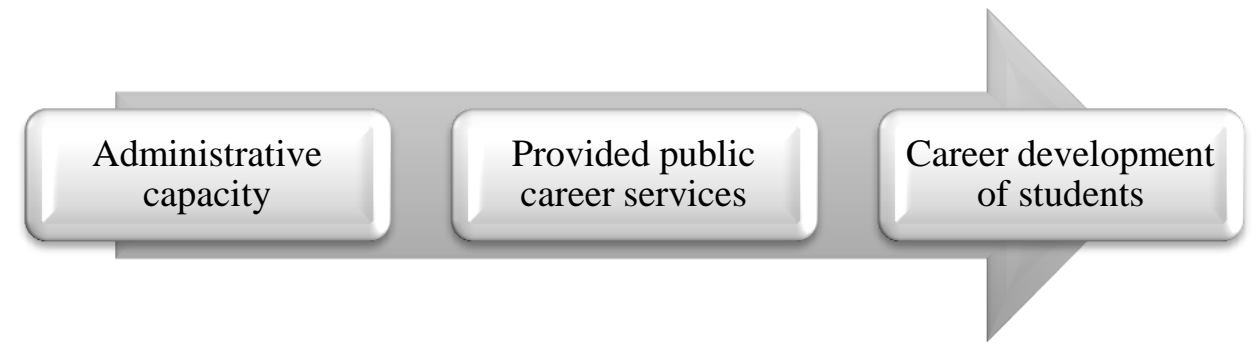

Figure 2. Role of administrative capacity for the provision of services

The main opportunities for building and developing the administrative capacity of career centers can be reduced to (Figure 3):

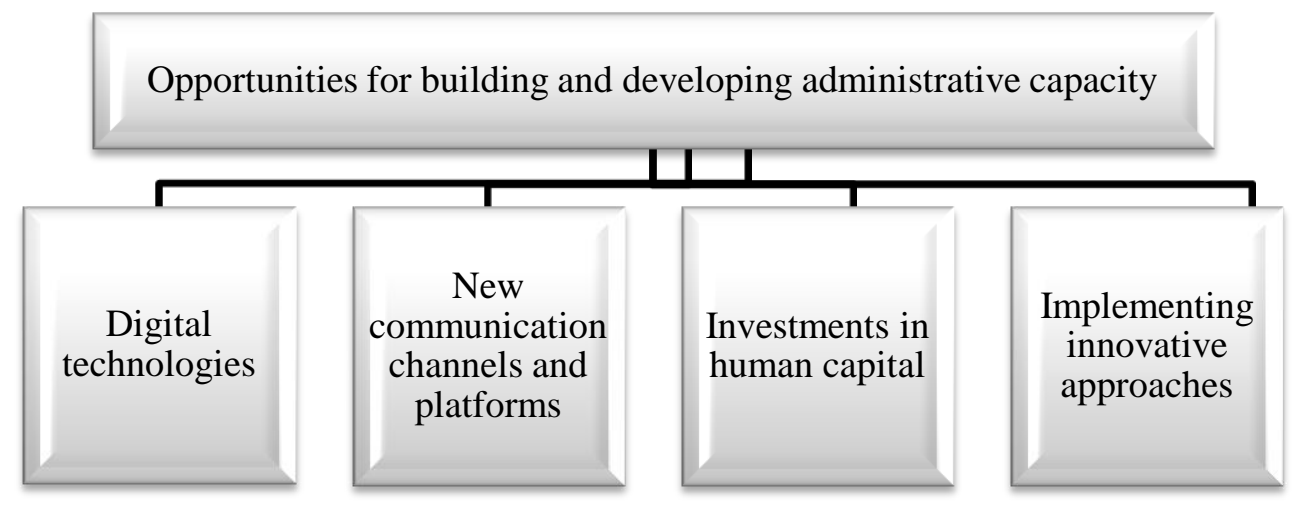

Figure 3. Opportunities for building and developing administrative capacity

- Implementing new digital technologies to deliver services. This includes the use of new methods of searching for information in a web environment. One of the latest researches in this direction is by Milev, who focuses on the possibilities of applying Internet monitoring in public organizations [5]. This is a very topical issue, especially if surveys are made on Internet publications about the correctness and reputation of employers who hire graduate students.

- New communication channels and platforms to inform and share opportunities and activities with students and employers. This includes the development of own web platforms for job placement and job posting; the use of social networks; warehouse systems; Internet monitoring systems; event management systems, etc.;

- Investments in human capital related to upgrading qualifications and employee training. Each career consultant should have the opportunity for further qualification and training. One of the reasons is the constant changes in the labor market trends. Others are related to the development of the concept and basic model of administrative service described by Daskalova [6];

- Implement innovative approaches to ongoing initiatives, events and forums. In recent years, employers have become more and more willing and able to participate permanently in various initiatives of higher education institutions. For these reasons, career centers should be aware of and implement new and innovative approaches to organizing such activities.

Along with the factors that determine the establishment and development of the administrative capacity of the career centers, the question of its measurement is also raised. Measuring and assessing administrative capacity is often the focus of research by leading researchers. Regarding public 
organizations, Kirilova points out that "the evaluation should be carried out periodically" [7]. The same author points out specific methodological tools and software implementation options for the methods. Some of them that can be used to evaluate career centers are:

- A general description of each of the proposed assessment methods;

- Purpose and basic functionality;

- Indicators;

- Information sources;

- Final evaluation;

- Algorithms for the final evaluation, etc.

Developing a methodology for assessing the capacity of career centers is a very serious research task. It deserves great attention and can provide several responses to improve processes. In order to solve it, it is necessary to describe in detail all the processes involved. Then a link should be made between the components of administrative capacity and the characteristics of each process. The third step is to target a specific system of indicators to form capacity assessment. The fourth step should be a functioning feedback system. It can manage changes and achieve the values of the key indicators.

\section{CONCLUSIONS}

In conclusion, it is important to draw attention to a few basic summaries from the analyzes made:

- Tasks at career centers will change dynamically in the future;

- Building and developing administrative capacity is a permanent task. The system of services offered by the career center depends largely on its solution;
- The digitization of the services provided, and the use of digital communication channels requires investment in training and additional qualifications of career consultants;

- The human factor is becoming a major factor in maintaining the capacity built and achieving high efficiency in the business.

\section{REFERENCES}

1. http://iccd.unwe.bg/

2. http://www.unwe.bg

3. Kirilova, K., Challenges to the Administrative Service of Municipalities in Bulgaria, 2018, Research Papers of UNWE, Issue 4 / 2018, ISSN (print): 0861-9344, ISSN (online): 2534-8957, pp. 229-245.

4. Milev, P., Technological Issues of Storing Dynamic Data in a Relational Database on Research Projects, Trakia Journal of Sciences, Vol. 13, Suppl. 1, pp 22-25, 2015, ISSN 1313-7069 (print), 1313-3551 (online).

5. Milev, P., Opportunities for Implementing Internet Monitoring in Public Organizations, Economic and Social Alternatives, Issue 2, 2018, ISSN 13146556.

6. Daskalova, T., The human resources in the administration of "one-stop-shop", The Human Resources in the Panorama of Labor: a magazine for labor and social relations, Issue 2, 2009, pp. 26-35, ISSN 1312-305X.

7. Kirilova, K., Methodological Issues in Assessing the Capacity of Local Authorities for Developing and Delivering Electronic Services, Trakia Journal of Sciences, Vol. 11, Suppl. 1, 2013, pp. 85 - 88, ISSN 13137069 (print), 1313-3551 (online). 